Portland State University

PDXScholar

\title{
Genotypic Diversity and Host-Specificity of Frankia Bacteria Associated with Sympatric Populations of Alnus rubra and Alnus rhombifolia in Oregon
}

\author{
Mehmet Ali Balkan \\ Portland State University, memo.balkan@gmail.com \\ Nathan U. Stewart \\ Portland State University \\ Emily S. Kauffman \\ Portland State University, emilyskauffman@gmail.com \\ Emily R. Wolfe \\ Portland State University \\ Daniel J. Ballhorn \\ Portland State University, ballhorn@pdx.edu
}

Follow this and additional works at: https://pdxscholar.library.pdx.edu/bio_fac

Part of the Biology Commons, and the Ecology and Evolutionary Biology Commons Let us know how access to this document benefits you.

\section{Citation Details}

Balkan, M. A., Stewart, N. U., Kauffman, E. S., Wolfe, E. R., \& Ballhorn, D. J. (2020). Genotypic Diversity and Host-Specificity of Frankia Bacteria Associated with Sympatric Populations of Alnus rubra and Alnus rhombifolia in Oregon. Northwest Science, 93(3-4), 244-252.

This Article is brought to you for free and open access. It has been accepted for inclusion in Biology Faculty Publications and Presentations by an authorized administrator of PDXScholar. Please contact us if we can make this document more accessible: pdxscholar@pdx.edu. 


\title{
Genotypic Diversity and Host-Specificity of Frankia Bacteria Associated with Sympatric Populations of Alnus rubra and Alnus rhombifolia in Oregon
}

\author{
Authors: Balkan, Mehmet A., Stewart, Nathan U., Kauffman, Emily S., \\ Wolfe, Emily R., and Ballhorn, Daniel J.
}

Source: Northwest Science, 93(3-4) : 244-252

Published By: Northwest Scientific Association

URL: https://doi.org/10.3955/046.093.0307

\begin{abstract}
BioOne Complete (complete.BioOne.org) is a full-text database of 200 subscribed and open-access titles in the biological, ecological, and environmental sciences published by nonprofit societies, associations, museums, institutions, and presses.
\end{abstract}

Your use of this PDF, the BioOne Complete website, and all posted and associated content indicates your acceptance of BioOne's Terms of Use, available at www.bioone.org/terms-of-use.

Usage of BioOne Complete content is strictly limited to personal, educational, and non - commercial use. Commercial inquiries or rights and permissions requests should be directed to the individual publisher as copyright holder.

\footnotetext{
BioOne sees sustainable scholarly publishing as an inherently collaborative enterprise connecting authors, nonprofit publishers, academic institutions, research libraries, and research funders in the common goal of maximizing access to critical research.
} 


\title{
Genotypic Diversity and Host-Specificity of Frankia Bacteria Associated with Sympatric Populations of Alnus rubra and Alnus rhombifolia in Oregon
}

\begin{abstract}
Biological nitrogen fixation is one of the most critical processes contributing to ecosystem productivity and stability on a global scale. In temperate climates of the northern hemisphere, plant-root associated bacteria of the genus Frankia are the major nitrogen fixers in forest environments. Trees belonging to the genus Alnus are the most widespread hosts of Frankia in the Pacific Northwest, and a myriad of biotic and abiotic factors can influence the robustness of this symbiosis. Host identity and bacterial strain are important features that can impact Alnus-Frankia association, but little is known about the interplay of intrageneric hosts that co-occur in natural settings. In this study we investigated the genetic diversity and host specificity of Frankia bacteria associated with sympatrically occurring populations of Alnus rubra (red alder) and Alnus rhombifolia (white alder) in Oregon. Based on sequence analysis of the nifH gene recovered from root nodules we found low overall bacterial diversity. One dominant Frankia genotype was associated with both host species, indicating a lack of strong host specificity in this system. Our results suggest that certain intrageneric plant hosts with overlapping distributions show cross-compatibility with symbiotic actinorhizal bacteria, and that low strain diversity of these bacteria can persist across mixed host populations.
\end{abstract}

Keywords: plant-microbe interactions, genotype, nitrogen-fixation, red alder, white alder.

\section{Introduction}

Nitrogen-fixing bacteria associated with plant roots are one of the primary sources of biological nitrogen inputs in terrestrial ecosystems. In temperate climates, bacteria of the genus Frankia are the major group that forms such symbioses with 24 actinorhizal angiosperm genera worldwide (Schwintzer and Tjepkema 1990, Benson and Silvester 1993). Members of the genus Alnus (alders) are the only known trees that form associations with Frankia bacteria, and Alnus rubra Bong. (red alder) is one of the most common tree species in the northwest (Franklin and Dyrness 1973). Accordingly, A. rubra represents a critical host for actinorhizal bacteria in the Pacific Northwest owing to its widespread distribution and relatively long lifespan compared to non-tree actinorhizal hosts in this region. Alders are pioneer tree species that can not only enhance soil nitrogen content,

\footnotetext{
${ }^{1}$ Author to whom correspondence should be addressed. Email: ballhorn@pdx.edu
}

but can also lower soil pH (Lawrence 1958), significantly increase soil organic matter (Tarrant and Miller 1963, Franklin et al. 1968, Bormann and DeBell 1981, Binkley et al. 1982, Binkley 1983), and improve the retention of important anions such as $\mathrm{PO}_{4}{ }^{3-}$ and $\mathrm{SO}_{4}{ }^{2-}$ (Johnson et al. 1986). Furthermore, the soil enhancing capacity of Frankia-associated Alnus species can also benefit neighboring trees of economic importance such as Pseudotsuga menziesii (Mirb.) Franco (Douglasfir) (Miller and Murray 1978) and Pinus species (Dai et al. 2004), with which they are sometimes interplanted for this purpose.

The performance of the actinorhizal symbiosis can vary significantly depending on host plantbacterial genotype combinations (Wheeler et al. 1986, Weber et al. 1987). While a number of different factors can influence the genotypic diversity of Frankia including edaphic (Sheppard et al. 1989, Crannell et al. 1994, Nickel et al. 1999) and biogeographic (Khan et al. 2007, Põlme et al. 2014) factors, the effect of host identity is of particular interest and has been widely studied (van Dijk et 
al. 1988, Rouvier et al. 1996, Navarro et al. 1999, Vanden Heuvel et al. 2004, Huguet et al. 2004, Lipus and Kennedy 2011, Põlme et al. 2014). Four major host infection groups have been identified for Frankia based on their ability to form nodules within actinorhizal plant families (Baker 1987), though it has since become clear that strains do not always remain within the boundaries of this host-specific classification (Torrey 1990). Much of the work examining Frankia host specificity in Alnus has focused on strain compatibility across allopatric populations of different (Anderson et al. 2009, Lipus and Kennedy 2011, Põlme et al. 2014) or the same (Welsh et al. 2009) host species. Few studies have investigated genotypic diversity and host specificity of the bacterial symbiont in sympatric populations of different Alnus species (Anderson et al. 2009, Pokharel et al. 2011), beckoning the questions of how proximity, shared soil environment, and exposure to the same Frankia strain pool act to influence host colonization and specificity. Pokharel et al. (2011) conducted a comprehensive assessment of Frankia associated with 12 Alnus taxa-most of which do not typically co-occur in their natural habitats - growing sympatrically in an arboretum setting. Using Rep-PCR (repetitive element polymerase chain reaction) fingerprinting, Pokharel and colleagues (2011) generated genetic strain profiles for nodules collected from multiple individuals of each taxon. Strikingly, only three distinct strain groupings were observed, with Frankia associated with nine of the Alnus taxa comprising a single strain (I), associates of two other taxa comprising a second strain (II), and a single taxon associate comprising the third group (III), suggesting low genetic diversity and high intrageneric host cross-compatibility. In contrast, Anderson et al. (2009) observed a total of nine unique RFLP (restriction fragment length polymorphism) profiles generated from Frankia nodules from $A$. viridis and $A$. tenuifolia populations growing sympatrically in interior Alaska, three of which occurred on both hosts and three of each of the remaining six profiles occurring on either host. Interestingly, the most abundant genotypes in each of three sites were consistently those that were unique to each host suggesting a greater degree of host specificity for those profiles.
Given such mixed results, the paucity of more accurate and replicable molecular approaches (e.g., sequence-based genotyping), and the underrepresentation of some Alnus species in previous studies, there is a need to further investigate the diversity and host specificity of actinobacteria among sympatrically distributed populations of alders in natural settings. Of the four Alnus species that are native to the Pacific Northwest (including northern California), red alder (Alnus rubra) and white alder (Alnus rhombifolia Nutt.) are the most common (Little 1976) and have overlap in their distribution. Here we assessed the genetic diversity and host specificity of Frankia bacteria associated with the roots of sympatric populations of A. rubra and A. rhombifolia in western Oregon.

\section{Methods}

\section{Study Area}

Nodule-bearing roots were collected from both red and white alder from a site in Sherwood, western Oregon (Heaton Creek, Figure 1). Alder species were identified considering a set of traits including variation in leaf shape, flowers, and extent and speed of oxidation processes resulting in red coloration of scratched inner tree bark. Red alder periderm (in line with its common name) shows a faster and much more intense coloration in response to physical damage compared to white alder. In total, 28 white alder and 30 red alder samples were collected, with each sample originating from a different tree. Trees had diameters at breast height between 10 and $25 \mathrm{~cm}$. Both species of trees showed similar variation in diameter (red alder: $16.4 \pm 4.0$, white alder: 15.9 $\pm 4.7[$ mean $\pm \mathrm{SD}])$. Nodule bearing roots were collected from the upper soil level $(15 \mathrm{~cm})$ at a radius of $50 \mathrm{~cm}$ around each tree. Nodules were only collected from larger roots $(>1 \mathrm{~cm}$ in diameter) easily trackable to the specific sample tree or from finer roots that were clearly attached to these larger roots. After collection, the roots with nodules were stored in sealed zip lock bags and transported to the lab in a cooler $\left(4^{\circ} \mathrm{C}\right)$. Nodules were processed within 48 hours. 


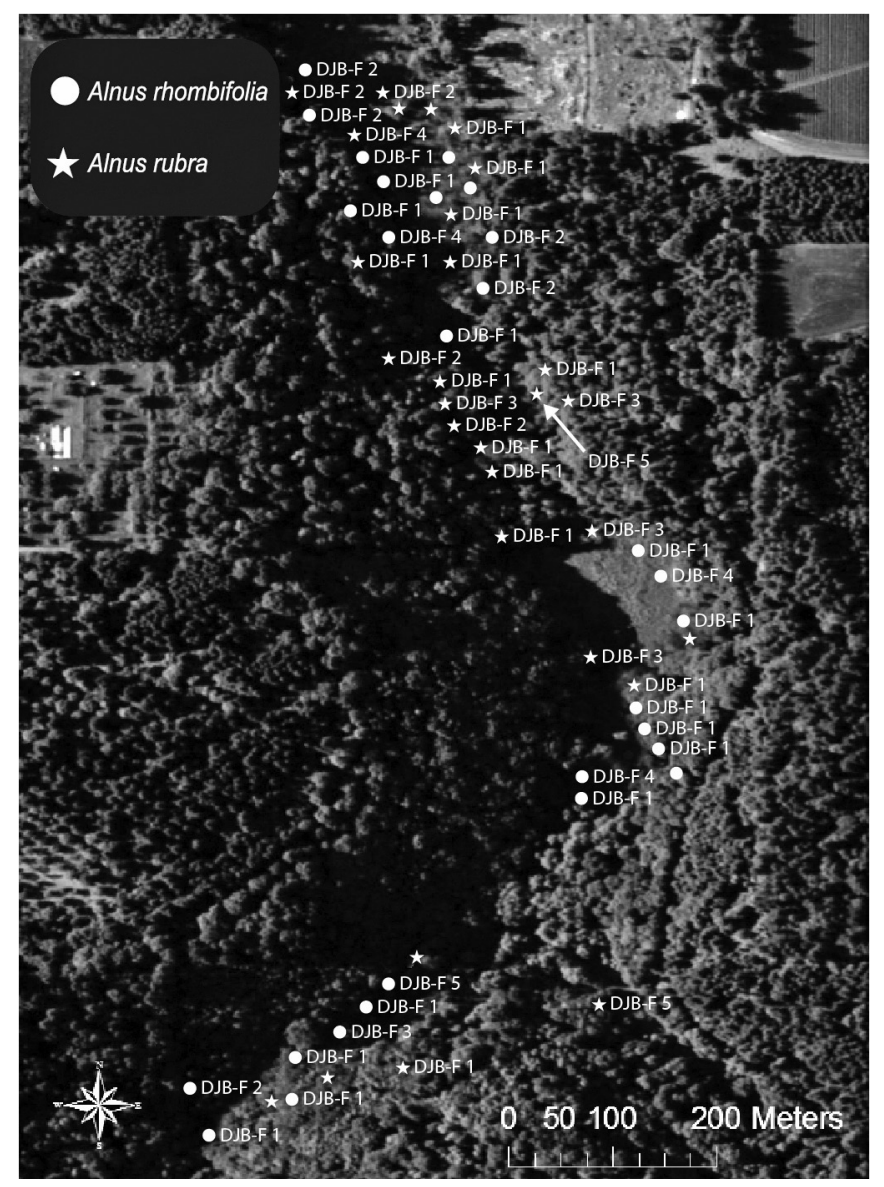

Figure 1. Map of collection site in western Oregon displaying locations of individual Alnus rubra and A. rhombifolia trees. Alnus rubra trees are labelled with star icons, $A$. rhombifolia trees with circles. Information on the associated Frankia genotype recovered from root nodules is provided for each tree. Icons without corresponding labels indicate trees from which nifH sequences were not obtained. repeated once more. After the second bleach wash, the washing process was repeated three more times with deionized water instead of bleach. After surface sterilization, a single nodule lobe of each sample was removed with a sterile scalpel. All single lobes were then transferred to $1.5 \mathrm{~mL}$ microcentrifuge tubes for DNA extraction using a sterile toothpick.

\section{DNA Extraction}

DNA was extracted from individual nodule lobes using the Sigma Tissue Extract-N-Amp Kit (Sigma-Aldrich, St. Louis, MO). Forty $\mu \mathrm{L}$ of extraction buffer were added into each 1.5 $\mathrm{mL}$ microcentrifuge tube containing an individual nodule lobe, which was then homogenized using a sterile micropestle. Lobe homogenates were centrifuged for 1 minute at 15,000 rpm $(21,130 \mathrm{x} \mathrm{g})$, and $20 \mu \mathrm{L}$ of supernatant from each tube transferred into an individual $0.2 \mathrm{~mL}$ PCR strip-tube. Strip-tubes containing extractions were placed in a thermal cycler and incubated at $65{ }^{\circ} \mathrm{C}$ for 10 minutes, followed by $95{ }^{\circ} \mathrm{C}$ for 10 minutes. Following incubation, $25 \mu \mathrm{L}$ of neutralization buffer were pipetted into each sample which were then briefly vortexed and stored at $4{ }^{\circ} \mathrm{C}$ until use.

\section{Surface Sterilization}

Roots and attached nodules were washed with deionized water to remove soil and organic matter. Nodules were then removed from roots with a sterile scalpel and placed into individual $14 \mathrm{~mL}$ sterile scintillation vials. Each vial was then filled with $10 \mathrm{~mL}$ of $10 \%$ bleach $(0.6 \%$ hypochlorite) solution and agitated in an orbital shaker at room temperature $\left(21^{\circ} \mathrm{C}\right)$ for 2 minutes at $140 \mathrm{rpm}$. After agitation, the bleach solution was decanted from each vial and the bleach washing process was

\section{PCR and Sequencing}

A 606 bp (base pair) portion of the nifH gene was amplified by PCR using Frankia-specific primers nifHfl (5'-GGC AAG TCC ACC ACC CAG C-3') and nifHr (5'-CTC GAT GAC CGT CAT CCG GC$\left.3^{\prime}\right)$. PCR reactions were set up in $24 \mu \mathrm{L}$ volumes containing $8.45 \mu \mathrm{L}$ PCR water, $12.5 \mu \mathrm{L}$ GoTaq Master Mix, $1.25 \mu \mathrm{L}$ BSA (1 mg/ $1 \mathrm{~mL}), 0.4 \mu \mathrm{L}$ of each primer $(10 \mu \mathrm{M})$, and $1 \mu \mathrm{L}$ of $1: 10$ diluted template. Reaction mixtures were then subjected to the following thermal cycling conditions: $96{ }^{\circ} \mathrm{C}$ for 5 minutes, 35 cycles at $95^{\circ} \mathrm{C}$ for 30 seconds, $60{ }^{\circ} \mathrm{C}$ for 30 seconds, $72{ }^{\circ} \mathrm{C}$ for 45 seconds, and 
a final extension at $72{ }^{\circ} \mathrm{C}$ for 7 minutes. Following PCR, all reaction products were visualized by gel electrophoresis. Successful PCR reactions were cleaned up using ExoSAP IT (USB Corp., Cleveland, $\mathrm{OH}$ ) according to the manufacturer's instructions. Sanger Sequencing was performed in both directions using the same primers used in PCR on an ABI 3730xl (Applied Biosystems, Foster City, CA) at Functional Biosystems, Inc. (Madison, WI).

\section{Sequence Processing}

Sequence data were visually inspected for quality, trimmed to $615 \mathrm{bp}$, and contigs generated from forward and reverse reads for each sample in Geneious version 10.2.3 (Kearse et al. 2012). Operational taxonomic units (OTUs) were generated by clustering contigs with $97 \%$ sequence similarity. This similarity cutoff was chosen because previous work has shown that Frankia genotypes are accurately placed in appropriate genomic groups at this threshold (Welsh et al. 2009, Mirza et al. 2009, Lipus and Kennedy 2011, Higgins and Kennedy 2012, Rodriguez et al. 2016). Representative sequences for each OTU group (i.e., genotype) were submitted to Genbank under the accession numbers MK105601-MK105605. The OTUs were then aligned using MAFFT version 7.309 (Katoh and Standley 2013). The nifH sequence of Frankia causuarinae strain Ccl3 (Normand et al. 2007) was downloaded from GenBank and included in the alignment as an outgroup. The ends of the alignments were trimmed to ensure each sequence was of the same length.

\section{Phylogenetic Analysis and Statistics}

To determine the optimal nucleotide substitution model for use in phylogenetic analysis, the alignment of OTUs created from both Alnus spp. at the $97 \%$ similarity threshold was analyzed using PartitionFinder version 2.1.1 (Lanfear et al. 2016). The entire alignment was treated as a single data block, "models" and "schemes" were set to all, and model selection was done based on the corrected Akaike Information Criterion. This analysis indicated that a general time reversible model with an estimation of invariant sites $(\mathrm{GTR}+\mathrm{I})$ was the best fit, and this model was used in both maximum likelihood and Bayesian tree building.

Maximum likelihood trees were built in Geneious using RAxML version 8.2.11 (Stamatakis 2014) with the "GTR CAT I" model setting and the Rapid Bootstrapping algorithm; 10,000 bootstrap replicates were performed, and the consensus trees were built with a $25 \%$ bootstrap support minimum. Bayesian trees were built using BEAST version 1.8.4 (Drummond et al. 2012) with the GTR+I nucleotide model. A strict clock model was used, along with a coalescent constant-population tree prior. The program was run with chain lengths of 10,000,000 states, with sampling every 1,000 states. Maximum clade credibility trees were generated in Tree Annotator with a 10\% burn-in.

The software EstimateS 9.1.0 (Colwell 2013) was used to estimate the true richness of Frankia genotypes associated with $A$. rubra and $A$. rhombifolia. The Chao 2 estimator was computed on the basis of 500 randomizations of sample order without replacement. To assess whether the host identity significantly influenced the co-occurrence of the two most frequently observed Frankia genotypes, Fisher's Exact Probability Test was performed.

\section{Results}

\section{nifH Sequence Analysis}

We sequenced a portion of the nifH gene from Frankia nodules associated with the roots of 28 Alnus rhombifolia and 30 Alnus rubra individuals in order to assess the genetic diversity and level of host specificity of these actinobacteria in sympatric populations of their hosts. Of the 58 nodules processed we successfully generated nifH sequences for 47 , which were comprised of five OTUs (herein referred to as genotypes) at $97 \%$ sequence similarity across both tree species. Sequences derived from both $A$. rubra and A. rhombifolia associated nodules clustered into each of five genotypes at varying proportions with $A$. rubra derived sequences outnumbering $A$. rhombifolia derived sequences in four out of the five genotype groupings (Table 1). The calculated Chao 2 richness estimator was identical to the observed richness of 
TABLE 1. Abundance of Frankia genotypes associated with host Alnus species.

\begin{tabular}{lccccc}
\hline \multirow{2}{*}{ Host Species } & \multicolumn{5}{c}{ Frankia Genotype } \\
\cline { 2 - 6 } & DJB-F1 $^{1}$ & DJB-F2 & DJB-F3 & DJB-F4 & DJB-F5 $^{2}$ \\
\hline Alnus rubra & 12 & 3 & 5 & 1 & 2 \\
Alnus rhombifolia & 13 & 6 & 1 & 3 & 1 \\
\hline
\end{tabular}

${ }^{1}$ Identical to genotype KL2 (GenBank accession GU810474.1) described in Kennedy et al. 2010.

${ }^{2}$ Identical to genotype KL1.16 (GenBank accession GU810479.1) described in Kennedy et al. 2010.

five Frankia genotypes shared by the two Alnus populations, illustrating that sampling of nodules was adequate to represent true genotypic richness. More than $50 \%$ of sequences derived from both Alnus host species clustered into one dominant genotype (DJB-F1), which was associated with trees that were heterogeneously distributed across the site (Figure 1). Similarly, trees associated with the other four genotypes (DJB-F2-DJB-F5) also exhibited heterogeneous spatial distribution. Upon comparing the Alnus-associated Frankia genotypes in our study to those characterized in other studies conducted in our region (Kennedy et al. 2010, Lipus and Kennedy 2011), we discovered that two of our genotypes (DJB-F1 and DJB-F5) were identical to two described previously (KL2 and KL1.6 respectively). The results of the Fisher's Exact Probability Test $(P=0.618)$ indicate that no systematic association exists between Alnus species and occurrence of Frankia genotype in at this site.

\section{Phylogenetic Analysis}

Both maximum likelihood and Bayesian phylogenetic analyses of the five Frankia genotypes recovered from A. rubra and A. rhombifolia yielded trees with identical topologies (Figure 2 ). The genotypes are clustered into two major clades, with one clade consisting of DJB-F3, and the other consisting of two monophyletic subclades containing two of each of the remaining four genotypes (DJB-F1, DJB-F5; and DJB-F2, DJB-F4, respectively). Relatively high bootstrap support values and posterior probabilities support the stability of these groupings.

\section{Discussion}

The goal of the current study was to assess genetic diversity and host specificity of actinorhizal Frankia bacteria associated with the roots of two co-occurring Alnus taxa. Our findings suggest that host identity is not a strong driver of Frankia genotype abundance associated with sympatric populations of Alnus rubra and A. rhombifolia. Whether or not these findings are applicable on a larger scale remains elusive as we were limited to a single location in western Oregon. Still, to the best of our knowledge, this is the first study comparing host-Frankia associations of these species at a natural site.

Similar to other studies we found low overall diversity of Frankia (Benson et al. 1996, Clawson et al. 1997, Oakley et al. 2004, Vanden Heuvel et al. 2004, Lipus and Kennedy 2011, Pokharel et al. 2011) with a single dominant genotype across the sampling site. Interestingly, two of the genotypes recovered in the current study were identical to two described in previous studies (Table 1) that were found at sites between $50 \mathrm{~km}$ and $115 \mathrm{~km}$ from the current study site. Remarkably these matching genotypes correspond to the most abundant genotype in our study and the two most abundant in those of Kennedy et al. (2010) and Lipus and Kennedy (2011), further underscoring the regional low diversity of Alnus-associated Frankia. There were no genotypes that were unique to either host, and no significant association between the abundance of genotypes and host species was observed indicating a lack of host specificity in this system. A similar pattern was observed by Pokharel et al. (2011) who found that Rep-PCR profiles (i.e. genotypes) of Frankia associated with nine out of 12 Alnus taxa in a common garden setting were identical. Likewise, Oakley et al. (2004) performed a sequence-based analysis of Frankia associated with several co-occurring Ceanothus species and reported a high level of sequence homogeneity across hosts despite not having clustered similar sequences into OTUs, which would have likely further reduced the observed diversity. Interest-

\section{Balkan et al.}




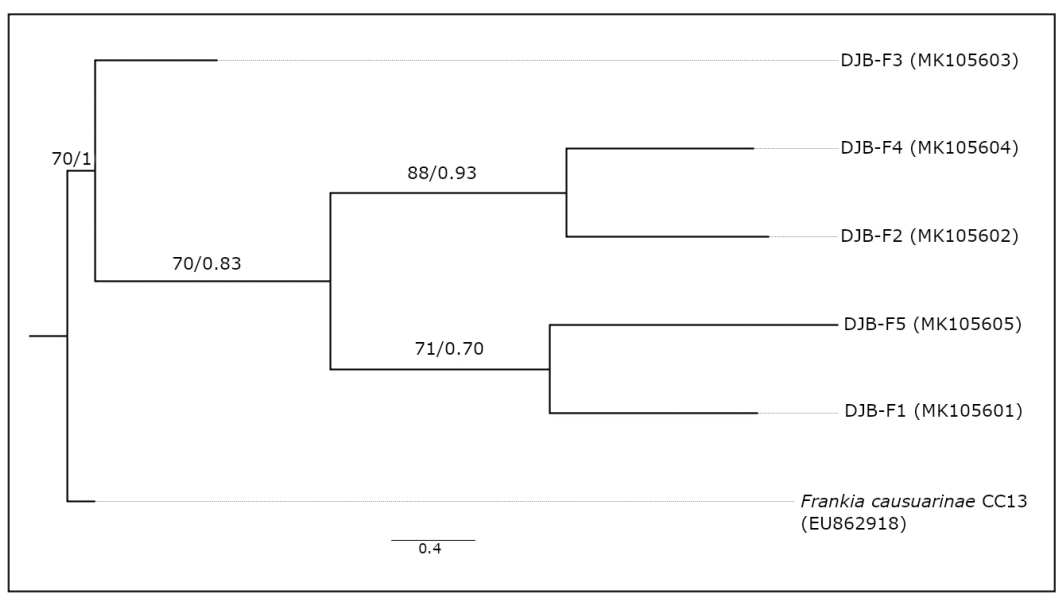

Figure 2. Maximum likelihood tree based on nifH gene sequences generated from Frankia nodules associated with Alnus rubra and A. rhombifolia. Branch labels reflect bootstrap support values for ML (maximum likelihood), followed by posterior probabilities for Bayesian analyses. A sequence for Frankia causuarianae $\mathrm{Cc} 13$ was used as an outgroup.

ingly, allopatric populations have also exhibited intrageneric host cross-compatibility with symbionts in Alnus (Welsh et al. 2009, Lipus and Kennedy 2011, Põlme et al. 2014). In contrast, the findings of Anderson et al. (2009) revealed that the most abundant Frankia strains (based on RFLP profiles) recovered from overlapping A. viridis and $A$. tenuifolia were unique to each host, in that case indicating a high degree of host specificity in their study site.

Whereas strict host specificity appears to be more the exception than the rule within intrageneric hosts (especially those that are sympatrically distributed), variation in this phenomenon is likely to be influenced by host phylogeny and not simply taxonomic identity. This was more recently highlighted in a large-scale global assessment of Frankia associated with 22 Alnus species on four continents by Põlme et al. (2014). From their investigation, Põlme and associates discovered that host phylogeny was the primary driver of Frankia assemblages worldwide and that the majority of recovered genotypes were generalists, with a few that were strongly host specific. This may explain the mixed results obtained across other studies comparing the Frankia assemblages of co-occurring hosts of the same genus, whereby different host species combinations may produce different outcomes in respect to symbiont affinity. The Alnus species in our study are more closely related compared to other similar studies (Chen and Li 2004) in which a high degree of host preference (Lipus and Kennedy 2011) or host specificity (Anderson et al. 2009) were found, supporting the idea that host phylogeny may reflect the degree of homogeneity in Frankia populations associated with co-occuring host species. It is also noteworthy that Põlme et al. (2014) found that Frankia phylogeny did not significantly influence the identity of associated hosts, reinforcing the idea that the Alnus host is selecting the symbiont and not vice versa. This may also explain the oddity of the dominant genotype in our study being most closely related to the rarest in our study (Figure 2). In other words as suggested above, perhaps selective initiation of the actinorhizal mutualism depends on factors not bound to symbiont phylogeny, or at least not to the degree that is revealed by variation in the nifH gene.

While certain key features such as low overall diversity with few dominant genotypes appear to be consistent across studies, the reason for this phenomenon is still elusive. One possible explanation for the low diversity of host-associated Frankia are potential limitations in resolution of using single standard marker genes like nifH. However, the nifH gene currently represents by far the most utilized marker for studying genotypic variation in nitrogen-fixing bacteria-including Frankia - and many key studies on Frankia diversity available today have used this marker (Welsh et al. 2009, Mirza et al. 2009, Kennedy et al. 2010, Põlme et al. 2014, Rodriguez et al. 2016). Other new markers (or combinations thereof) such as the pgk region for example (Pozzi et al. 
2018) are promising to provide greater analytical depth but are little tested so far or in the case of multiple markers often yield conflicting results. While nifH has limitations it still is useful to provide data with the particlar advantage of being easily comparable to existing studies databases and allowing the specific targeting of Frankia bacteria in environmental samples. Ultimately, full genomic comparisons will eventually yield the best metric for deriving genotypic grouping of Frankia strains.

Another potential explanantion for the relatively low diversity of host-associated Frankia is that only few Frankia genotypes provide significant adaptive advantages to host plants in nature. At this point, the question why and under which conditions host associations with few dominant Frankia genotypes - as opposed to diverse consortia-provide an adaptive advantage to host fitness remains unsanswered. Bioassays with specific host-Frankia associations under controlled conditions would provide useful tools to study host-Frankia specificity (Lipus and Kennedy

\section{Literature Cited}

Anderson, M. D., R. W. Ruess, D. D. Myrold, and D. L. Taylor. 2009. Host species and habitat affect nodulation by specific Frankia genotypes in two species of Alnus in interior Alaska. Oecologia 160:619-630.

Baker, D. D. 1987. Relationships among pure cultured strains of Frankia based on host specificity. Physiologia Plantarum 70:245-248.

Benson, D. R., and W. Silvester. 1993. Biology of Frankia strains, actinomycete symbionts of actinorhizal plants. Microbiological reviews 57:293-319.

Benson, D. R., D. W. Stephens, M. L. Clawson, and W. B. Silvester. 1996. Amplification of 16S rRNA genes from Frankia strains in root nodules of Ceanothus griseus, Coriaria arborea, Coriaria plumosa, Discaria toumatou, and Purshia tridentata. Applied and Environmental Microbiology 62:2904-2909.

Binkley, D. 1983. Ecosystem production in Douglas-fir plantations: interaction of red alder and site fertility. Forest Ecology and Management 5:215-227.

Binkley, D., K. Cromack, and R. L. Fredriksen. 1982. Nitrogen accretion and availability in some snowbrush ecosystems. Forest Science 28:720-724.

Bormann, B. T., and D. S. DeBell. 1981. Nitrogen content and other soil properties related to age of red alder stands. Soil Science Society of America Journal 45:428-432.

250 Balkan et al.
2011), but whether or not different symbioses provide actual advantages or disadvantages in nature requires bioassays at natural sites. Thus, future efforts would benefit from the inclusion of multiple combinations of co-occuring host species, and detailed studies on the prevalence of specific host-Frankia combinations under variable micro-climatic conditions in nature. Combining such outdoor studies with measuring phenotypic responses of host plants in combinatorial experiments under controlled conditions will help illuminate the functional underpinnings of these unique associations.

\section{Acknowledgments}

Funding by the National Science Foundation (NSF) to DJB (grants IOS 1457369 and 1656057) is gratefully acknowledged. The authors would like to thank Christopher Diego for assistance with site map design, and gratefully acknowledge funding by the National Science Foundation (NSF) to DJB (grants IOS 1457369 and 1656057).

Chen, Z., and J. Li. 2004. Phylogenetics and biogeography of Alnus (Betulaceae) inferred from sequences of nuclear ribosomal DNA ITS region . International Journal of Plant Sciences 165:325-335.

Clawson, M. L., D. R. Benson, S. C. Resch, D. W. Stephens, and W. B. Silvester. 1997. Typical Frankia infect actinorhizal plants exotic to New Zealand. New Zealand Journal of Botany 35:361-367.

Colwell, R. K. 2013. EstimateS: Statistical estimation of species richness and shared species from samples. Version 9. Available online at http://purl.oclc.org/ estimates (accessed 25 Jun 2019).

Crannell, W. K., Y. Tanaka, and D. D. Myrold. 1994. Calcium and $\mathrm{pH}$ interaction on root nodulation of nursery-grown red alder (Alnus rubra Bong.) seedlings by Frankia. Soil Biology and Biochemistry 26:607-614.

Dai, Y. M., X. Y. He, C. G. Zhang, and Z. Z. Zhang. 2004. Characterization of genetic diversity of Frankia strains in nodules of Alnus nepalensis (D. Don) from the Hengduan Mountains on the basis of PCR-RFLP analysis of the nifD-nifK IGS. Plant and Soil 267:207-212.

Drummond, A. J., M. A. Suchard, D. Xie, and A. Rambaut. 2012. Bayesian phylogenetics with BEAUti and the BEAST 1.7. Molecular Biology and Evolution 29:1969-1973. 
Franklin, J. F., and C. T. Dyrness. 1973. Natural vegetation of Oregon and Washington. USDA Forest Service General Technical Report PNW-GTR-008. Pacific Northwest Research Station, Portland, OR.

Franklin, J. F., C. T. Dyrness, D. G. Moore, and R. F. Tarrant. 1968. Chemical soil properties under coastal Oregon stands of alder and conifers. In J. M. Trappe (editor), Biology of Alder: Proceedings of Northwest Scientific Association Annual Symposium, Pacific Northwest Forest and Range Experiment Station, USDA Forest Service, Portland, Oregon. Pp. 157-172.

Higgins, L. M., and P. G. Kennedy. 2012. Symbiotic Frankia bacteria in Alnus forests in Mexico and the United States of America: is geographic location a good predictor of assemblage structure? Botany 90:423-431.

Huguet, V., M. Mergeay, E. Cervantes, and M. P. Fernandez. 2004. Diversity of Frankia strains associated to Myrica gale in Western Europe: impact of host plant (Myrica vs. Alnus) and of edaphic factors. Environmental Microbiology 6:1032-1041.

Johnson, D. W., D. W. Cole, H. Van Miegroet, and F. W. Horng. 1986. Factors affecting anion movement and retention in four forest soils. Soil Science Society of America Journal 50:776-783.

Katoh, K., and D. M. Standley. 2013. MAFFT Multiple sequence alignment software version 7: improvements in performance and usability. Molecular Biology and Evolution 30:772-780.

Kearse, M., R. Moir, A. Wilson, S. Stones-Havas, M. Cheung, S. Sturrock, S. Buxton, A. Cooper, S. Markowitz, C. Duran, T. Thierer, B. Ashton, P. Meintjes, and A. Drummond. 2012. Geneious Basic: an integrated and extendable desktop software platform for the organization and analysis of sequence data. Bioinformatics 28:1647-1649.

Kennedy, P. G., M. G. Weber, and A. A. Bluhm. 2010. Frankia bacteria in Alnus rubra forests: genetic diversity and determinants of assemblage structure. Plant and Soil 335:479-492.

Khan, A., D. D. Myrold, and A. K. Misra. 2007. Distribution of Frankia genotypes occupying Alnus nepalensis nodules with respect to altitude and soil characteristics in the Sikkim Himalayas. Physiologia Plantarum 130:364-371.

Lanfear, R., P. B. Frandsen, A. M. Wright, T. Senfeld, and B. Calcott. 2016. PartitionFinder 2: new methods for selecting partitioned models of evolution for molecular and morphological phylogenetic analyses. Molecular Biology and Evolution 34:772-773.

Lawrence, D. B. 1958. Glaciers and vegetation in southeastern Alaska. American Scientist 46:81-122.

Lipus, A., and P. G. Kennedy. 2011. Frankia assemblages associated with Alnus rubra and Alnus viridis are strongly influenced by host species identity. International Journal of Plant Sciences 172:403-410.
Little, E. L. 1976. Atlas of United States Trees, Vol. 3: Minor Western Hardwoods. USDA Forest Service, Washington, DC.

Miller, R. E., and M. D. Murray. 1978. The effects of red alder on growth of Douglas-fir. USDA Forest Service General Technical Report PNW-70. Pacific Northwest Research Station, Portland, OR.

Mirza, B. S., A. Welsh, G. Rasul, J. P. Rieder, M. W. Paschke, and D. Hahn. 2009. Variation in Frankia populations of the Elaeagnus host infection group in nodules of six host plant species after inoculation with soil. Microbial Ecology 58:384-393.

Navarro, E., T. Jaffre, D. Gauthier, F. Gourbiere, G. Rinaudo, P. Simonet, and P. Normand. 1999. Distribution of Gymnostoma spp. microsymbiotic Frankia strains in New Caledonia is related to soil type and to host-plant species. Molecular Ecology 8:1781-1788.

Nickel, A., D. Hahn, K. Zepp, and J. Zeyer. 1999. In situ analysis of introduced Frankia populations in root nodules of Alnus glutinosa grown under different water availability. Canadian Journal of Botany 77:1231-1238.

Normand, P., P. Lapierre, L. S. Tisa, J. P. Gogarten, N. Alloisio, E. Bagnarol, C. a Bassi, A. M. Berry, D. M. Bickhart, N. Choisne, A. Couloux, B. Cournoyer, S. Cruveiller, V. Daubin, N. Demange, M. P. Francino, E. Goltsman, Y. Huang, O. R. Kopp, L. Labarre, A. Lapidus, C. Lavire, J. Marechal, M. Martinez, J. E. Mastronunzio, B. C. Mullin, J. Niemann, P. Pujic, T. Rawnsley, Z. Rouy, C. Schenowitz, A. Sellstedt, F. Tavares, J. P. Tomkins, D. Vallenet, C. Valverde, L. G. Wall, Y. Wang, C. Medigue, and D. R. Benson. 2007. Genome characteristics of facultatively symbiotic Frankia sp. strains reflect host range and host plant biogeography. Genome Research 17:7-15.

Oakley, B., M. North, J. F. Franklin, B. P. Hedlund, and J. T. Staley. 2004. Diversity and distribution of Frankia strains symbiotic with Ceanothus in California. Applied and Environmental Microbiology 70:6444-6452.

Pokharel, A., B. S. Mirza, J. O. Dawson, and D. Hahn. 2011. Frankia populations in soil and root nodules of sympatrically grown Alnus taxa. Microbial Ecology 61:92-100.

Põlme, S., M. Bahram, U. Kõljalg, and L. Tedersoo. 2014. Global biogeography of Alnus-associated Frankia actinobacteria. New Phytologist 204:979-988.

Pozzi, A. C., H. H. Bautista-Guerrero, S. S. Abby, A. Herrera-Belaroussi, D. Abrouk, P. Normand, F. Menu, and M. P. Fernandez. 2018. Robust Frankia phylogeny, species delineation and intraspecies diversity based on Multi-Locus Sequence Analysis (MLSA) and Single-Locus Strain Typing (SLST) adapted to a large sample size. Systematic and Applied Microbiology 41:311-323. 
Rodriguez, D., T. M. Guerra, M. R. J. Forstner, and D. Hahn. 2016. Diversity of Frankia in soil assessed by Illumina sequencing of nifH gene fragments. Systematic and Applied Microbiology 39:391-397.

Rouvier, C., Y. Prin, P. Reddell, P. Normand, and P. Simonet. 1996. Genetic diversity among Frankia strains nodulating members of the family Casuarinaceae in Australia revealed by PCR and restriction fragment length polymorphism analysis with crushed root nodules. Applied and Environmental Microbiology 62:979-985.

Schwintzer, C. R., and J. D. Tjepkema. 1990. The Biology of Frankia and Actinorhizal Plants. Academic Press, Inc., San Diego, CA.

Sheppard, L. J., J. E. Hooker, C. T. Wheeler, and R. I. Smith. 1989. Glasshouse evaluation of the growth of Alnus rubra and Alnus glutinosa on peat and acid brown earth soils when inoculated with four sources of Frankia. In F. A. Skinner (editor), Nitrogen Fixation with Non-Legumes, Springer Netherlands, Dordrecht. Pp. 35-46.

Stamatakis, A. 2014. RAxML version 8: a tool for phylogenetic analysis and post-analysis of large phylogenies. Bioinformatics 30:1312-1313.

Tarrant, R., and R. Miller. 1963. Accumulation of organic matter and soil nitrogen beneath a plantation of red alder and Douglas-fir. Soil Science Society of America Proceedings 27:231-234.

Received 11 December 2018

Accepted 01 October 2019
Torrey, J. G. 1990. Cross-inoculation groups within Frankia and host-endosymbiont associations. In C. R. Schwintzer and J. D. Tjepkema (editors), The Biology of Frankia and Actinorhizal Plants, Academic Press, Inc., San Diego, CA. Pp. 83-106.

van Dijk, C., A. Simmer, and A. Weber. 1988. Host range differentiation of spore-positive and spore-negative strain types of Frankia in stands of Alnus glutinosa and Alnus incana in Finland. Physiologia Plantarum 72:349-358.

Vanden Heuvel, B. D., D. R. Benson, E. Bortiri, and D. Potter. 2004. Low genetic diversity among Frankia spp. strains nodulating sympatric populations of actinorhizal species of Rosaceae, Ceanothus (Rhamnaceae) and Datisca glomerata (Datiscaceae) west of the Sierra Nevada (California). Canadian Journal of Microbiology 50:989-1000.

Weber, A., E.-L. Nurmiaho-Lassila, and V. Sundman. 1987. Features of the intrageneric Alnus-Frankia specificity. Physiologia Plantarum 70:289-296.

Welsh, A. K., J. O. Dawson, G. J. Gottfried, and D. Hahn. 2009. Diversity of Frankia populations in root nodules of geographically isolated Arizona alder trees in central Arizona (United States). Applied and Environmental Microbiology 75:6913-6918.

Wheeler, C. T., J. E. Hooker, A. Crowe, and A. M. M. Berrie. 1986. The improvement and utilization in forestry of nitrogen fixation by actinorhizal plants with special reference to Alnus in Scotland. Plant and Soil 90:393-406.

\section{Balkan et al.}

